\title{
Brain Permeability of Bilobalide as Probed by Microdialysis Before and After Middle Cerebral Artery Occlusion in Mice
}

\author{
Dorothee Lang ${ }^{\mathrm{a},}$, Christian Ude ${ }^{\mathrm{b} \rrbracket}$, Mario Wurglics ${ }^{\mathrm{b}}$, Manfred Schubert-Zsilavecz ${ }^{\mathrm{b}}$ and Jochen Klein ${ }^{\mathrm{a}}$ \\ a Department of Pharmacology, Goethe University of Frankfurt, Max-von-Laue-Str. 9, 60438 Frankfurt, Germany. \\ ${ }^{\mathrm{b}}$ Department of Pharmaceutical Chemistry, Goethe University of Frankfurt, Max-von-Laue-Str. 9, 60438 Frankfurt, \\ Germany. \\ Q
}

Received, November 23, 2010; Revised, December 21, 2010; Accepted December 29, 2010; Published December 29, 2010.

\begin{abstract}
Purpose. Bilobalide is an active constituent of Ginkgo biloba and has shown neuroprotective effects in mice with cerebral ischemia. In the present study, we investigated brain permeability of bilobalide (i) in healthy mice and (ii) in mice before or after stroke. Methods. We have used in vivo microdialysis and LC-MS to estimate extracellular levels of bilobalide. $10 \mathrm{mg} / \mathrm{kg}$ of bilobalide was given by i.p. injection to control mice, and 60 minutes before and after middle cerebral artery occlusion (MCAO). Results. Bilobalide was already detectable in brain striatal microdialysates $10 \mathrm{~min}$ after i.p. administration and reached maximum levels $(19 \mathrm{ng} / \mathrm{mL}$, corresponding to $0.92 \mu \mathrm{M}$ ) after $40 \mathrm{~min}$. Maximum plasma bilobalide levels were $5.9 \mu \mathrm{M}$. After an ischemic insult, the drug could be dialysed with similar efficiency as in control mice indicating slow elimination from the ischemic brain. When the drug was given after MCAO, availability in the brain was low, but measurable, at approx. $10 \%$ of control values. Conclusions. Our data demonstrate that bilobalide easily crosses the blood brain barrier and reaches extracellular concentrations in the brain that allow efficient interaction with target molecules such as neurotransmitter receptors. Availability of the drug in ischemic tissue is high when given before ischemia, but severely limited after MCAO.
\end{abstract}

\section{INTRODUCTION}

Ginkgo biloba leave extracts such as EGb 761 are widely used in neurodegenerative disorders such as Alzheimer's disease and dementia of unknown causes [1,2]. In addition, animal models have shown that Ginkgo extract EGb 761 exerts beneficial effects in acute neurodegeneration caused by cerebral ischemia [3-5]. In our previous studies, bilobalide, a sesquiterpene trilactone and major constituent of the extract, had strong neuroprotective effects in vitro and in vivo under conditions of hypoxia and excitotoxicity. In hippocampal slices, bilobalide antagonized hypoxia- and NMDA receptor-induced choline release, and swelling and edema formation of hippocampal slices induced by oxygen-glucose deprivation [6,7]. In vivo, bilobalide (given i.p. at $10 \mathrm{mg} / \mathrm{kg}$ ) decreased infarct area as well as edema formation after middle cerebral artery occlusion (MCAO) in mice [8]. The mode of action of bilobalide is unknown although some evidence suggests interaction with GABAergic or glutamatergic pathways $[9,10]$ or with mitochondrial function $[11,12]$.

While these studies suggest adequate brain permeability of Ginkgo biloba constituents such as bilobalide, there was only limited information about the pharmacokinetics of individual compounds until very recently. In the last decade, sensitive LC-MS methods were developed to determine the constituents of the Ginkgo biloba extracts, and several reports have described plasma levels of bilobalide and ginkgolides after in vivo application. In human volunteers, oral intake of Ginkgo extracts (e.g. 120 mg EGb 761) yielded bilobalide plasma levels of $0.05-0.15 \mu \mathrm{M}$ [13-16]. In rats, oral administration of Ginkgo extracts and/or pure bilobalide caused dosedependent increases of bilobalide plasma levels from 0.5 to $7.5 \mu \mathrm{M}[13,17,18]$. Little information, however, is available on concentrations of Ginkgo constituents in the brain. We recently quantified brain levels of bilobalide and of flavonoid constituents of EGb 761 after oral administration in rats $[18,19]$; maximum bilobalide levels in brain homogenate were $98 \mathrm{ng} / \mathrm{g}$ corresponding to $0.4-0.5 \mu \mathrm{M}$ if the compound distributes freely in brain water [18]. Up to now, no information was available on extracellular concentrations of bilobalide which is of major importance for a drug that interacts with neurotransmitter receptors $[9,10]$.

Corresponding Author: Jochen Klein, Ph.D., Professor of Pharmacology and Clinical Pharmacy, Goethe University of Frankfurt, Biozentrum N260, Max-von-Laue-Str. 9, 60438 Frankfurt, Germany. E-mail: klein@em.uni-frankfurt.de 
The aim of this study, therefore, was to use microdialysis to quantify bilobalide in the extracellular fluid of the mouse brain. We used pure bilobalide to investigate brain permeability in healthy mice as well as in mice which sustained a middle cerebral artery occlusion (MCAO) before or after drug administration. MCAO, an experimental stroke model, was performed to mimic the potential therapeutic use of bilobalide in human patients. Our results demonstrate excellent brain availability of bilobalide when the drug is given before stroke, but very limited permeation into ischemic tissue if bilobalide was given after MCAO.

Novelty of the work. Bilobalide is a neuroprotective compound with potential value to treat neurodegenerative disease. This is the first study reporting extracellular levels of bilobalide in the brain. Our data demonstrate that the drug is sufficiently brain-permeable to reach low micromolar concentrations. Moreover, we show that bilobalide is available in ischemic brain when given before stroke; however, bioavailability in ischemic brain is much lower when given after stroke.

\section{METHODS}

\section{Animals}

Female CD-1 mice with a weight of 28-32 g (Charles River, Sulzfeld, Germany) were kept under standardized 12-h light/dark, temperature $\left(22{ }^{\circ} \mathrm{C}\right)$ and humidity $(70 \%)$ conditions, with food and water available ad libitum. All animal procedures were in accordance with German and European animal welfare acts. The study was registered with the Regierungspräsidium Darmstadt (permit \# 54-19c20/15-F8/17). All efforts were made to minimize animal numbers and animal suffering.

\section{Microdialysis experiments}

Mice were anesthetized with isoflurane (induction dose $4 \%$, maintenance dose $1-1.5 \% \mathrm{v} / \mathrm{v}$ ) in a $25 \% / 75 \%$ mixture of oxygen and nitrous oxide and placed in a stereotaxic frame. Self-made, Yshaped, concentric dialysis probes with an exchange length of $2.5 \mathrm{~mm}$ were implanted in the left striatum using the following coordinates (from bregma): AP $+0.5 \mathrm{~mm}$; $\mathrm{L}+2.2 \mathrm{~mm}$; DV $3.8 \mathrm{~mm}$ [20]. The mice were allowed to recover over night. On the next day, the microdialysis probes were perfused with artificial cerebrospinal fluid (aCSF; $147 \mathrm{mM} \mathrm{NaCl}, 4 \mathrm{mM} \mathrm{KCl}, 1.2 \mathrm{mM}$
$\mathrm{CaCl}_{2}$ and $1.2 \mathrm{mM} \mathrm{MgCl}_{2}$ ). The perfusion rate was $1.5 \mu \mathrm{L} / \mathrm{min}$ and efflux from the microdialysis probe was collected in intervals of $15 \mathrm{~min}$. After equilibration of $30 \mathrm{~min}$, animals were injected with bilobalide $(10 \mathrm{mg} / \mathrm{kg}$ i.p.; the drug was dissolved in saline containing 10\% DMSO), and dialysate samples were collected for four hours and assayed for bilobalide.

\section{Middle cerebral artery occlusion experiments (MCAO)}

For the experiments involving MCAO, mice were implanted with microdialysis probes as described above. On the next day, MCAO was performed as described previously, with minor modifications [21]. Briefly, a $20 \mathrm{~mm}$ monofilament nylon suture (Doccol Corporation, Redlands, CA, USA; diameter: $0.23 \pm 0.02 \mathrm{~mm}$ ) was inserted into the external carotid artery and gently advanced through the internal carotid artery until its tip occluded the origin of the middle cerebral artery. Perfusion of the microdialysis probe was started $60 \mathrm{~min}$ before MCAO, was sustained during surgery and was continued for several hours after MCAO. Bilobalide was injected i.p. $60 \mathrm{~min}$ before or after induction of ischemia at a dose of $10 \mathrm{mg} / \mathrm{kg}$ body weight. Animals were allowed to recover from anesthesia after MCAO, immediately after closure of the skin wound, and dialysis was continued.

MCAO was sustained for a period of $24 \mathrm{~h}$, after which the animals were deeply anesthetized with isoflurane and euthanized by decapitation. The brains were quickly removed, sectioned coronally into $1 \mathrm{~mm}$ slices with a tissue chopper, and stained with 2,3,5-triphenyl-tetrazolium chloride (TTC). TTC staining was used to verify successful stroke (Fig. 3) and correct probe location.

\section{LC-MS analysis of bilobalide}

Analysis of bilobalide was performed as previously described [18]. Briefly, HPLC analysis was carried out with an Agilent 1200 (Agilent Germany, Böblingen) using a Multo High 100 RP18， $5 \mu \mathrm{m}, 250$ x $4 \mathrm{~mm}$ column (CSChromatographie, Langerwehe, Germany). The eluent was $60 \%$ water $(0.1 \%$ formic acid $)$ and $40 \%$ methanol at an isocratic flow of $1 \mathrm{~mL} / \mathrm{min}$, and labetalol was used as internal standard. Detection of bilobalide was obtained by a MicroTOF-QII time-of-flight mass spectrometer equipped with an APCI source (Bruker Daltonik, Bremen, Germany) run in negative mode. The 
level of quantification for bilobalide was 0.25 $\mathrm{ng} / \mathrm{mL}$ in microdialysates.

\section{STATISTICS}

All values are represented as means \pm SEM of $n$ experiments. GraphPad Prism 5.0® was used for statistical analysis.

\section{RESULTS}

\section{In vitro-recovery of bilobalide}

To quantify recovery of bilobalide with our selfmade microdialysis probes, we perfused six different probes in a $10 \mu \mathrm{M}$ bilobalide solution (in aCSF) with or without $0.5 \mathrm{mM}$ albumin. After two hours of perfusion, the average concentration of bilobalide in aCSF was $209 \pm 67 \mathrm{pg} / \mu \mathrm{L}$ which corresponds to a recovery of $6.4 \%$. When 0.5 $\mathrm{mM}$ bovine serum albumin was present in the bilobalide solution, the average concentration in the dialysates was $197 \pm 74 \mathrm{pg} / \mu \mathrm{L}$, and recovery was $6.0 \%$. The data show that bilobalide did not display binding to albumin to a significant extent (Fig. 1).

\section{Extracellular levels of bilobalide in healthy mice}

To analyze brain permeability and bioavailability in the extracellular fluid (ECF), bilobalide was first applied i.p. to healthy mice at a dose of 10 $\mathrm{mg} / \mathrm{kg}$. Bilobalide was already detectable in the striatal dialysate $10 \mathrm{~min}$ after the application (Fig. 2) and reached a maximum concentration of 19.2 $\pm 8.8 \mathrm{pg} / \mu \mathrm{L}$ after $40 \mathrm{~min}$. Afterwards, bilobalide levels fell but the drug was still detectable in the brain after four hours at $5.5 \pm 1.5 \mathrm{pg} / \mu \mathrm{L}$. Corrected for in vitro-recovery $(6.4 \%$, see Fig. $1)$, these dialysate levels are equivalent to an extracellular concentrations of $0.92 \mu \mathrm{M}$ at $40 \mathrm{~min}$ past injection and $0.26 \mu \mathrm{M}$ at the end of the sampling time, respectively. Assuming first-order kinetics, the half-life of bilobalide in the brain as calculated from these data was $86.5 \mathrm{~min}$.

At $60 \mathrm{~min}$ past application, we also measured bilobalide in mouse plasma. The plasma level of bilobalide was $1.924 \mathrm{mg} / \mathrm{L}$ from which a plasma:brain ECF ratio of approximately 6.4:1 can be calculated.

\section{Middle cerebral artery occlusion (MCAO)}

In the second part of our study, we investigated brain levels of bilobalide when given before or after an ischemic insult. Fig. 3 shows representative brain slices which were obtained 24 hours after the MCAO experiment; healthy cells with intact mitochondria are stained red by TTC and areas with dead cells and insufficient mitochondrial activity show white color. The pictures demonstrate that the microdialysis probes (as indicated by black bars) were located in the core region of the stroke areas.

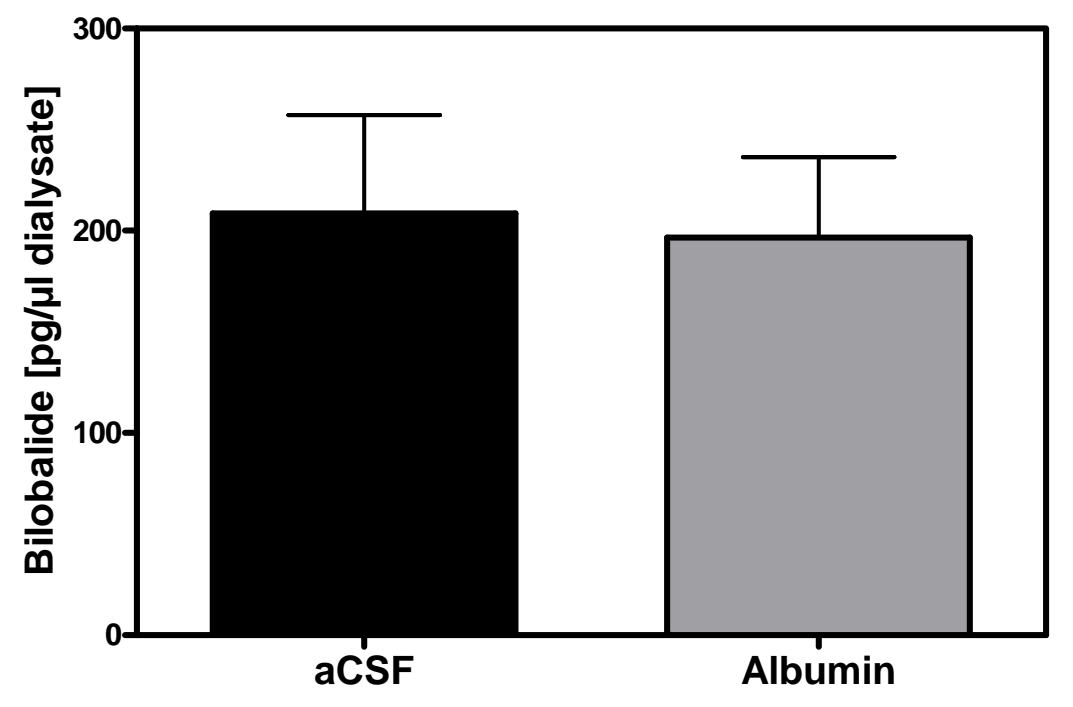

Figure 1. Recovery of bilobalide $(10 \mu \mathrm{M})$ in aCSF solution with or without $0.5 \mathrm{mM}$ albumin. The microdialysis probes were perfused with aCSF for 120 min each. Data are expressed as means $\pm \operatorname{SD}(n=6)$. Statistical analysis: $t$-test, $p=0.6$. 


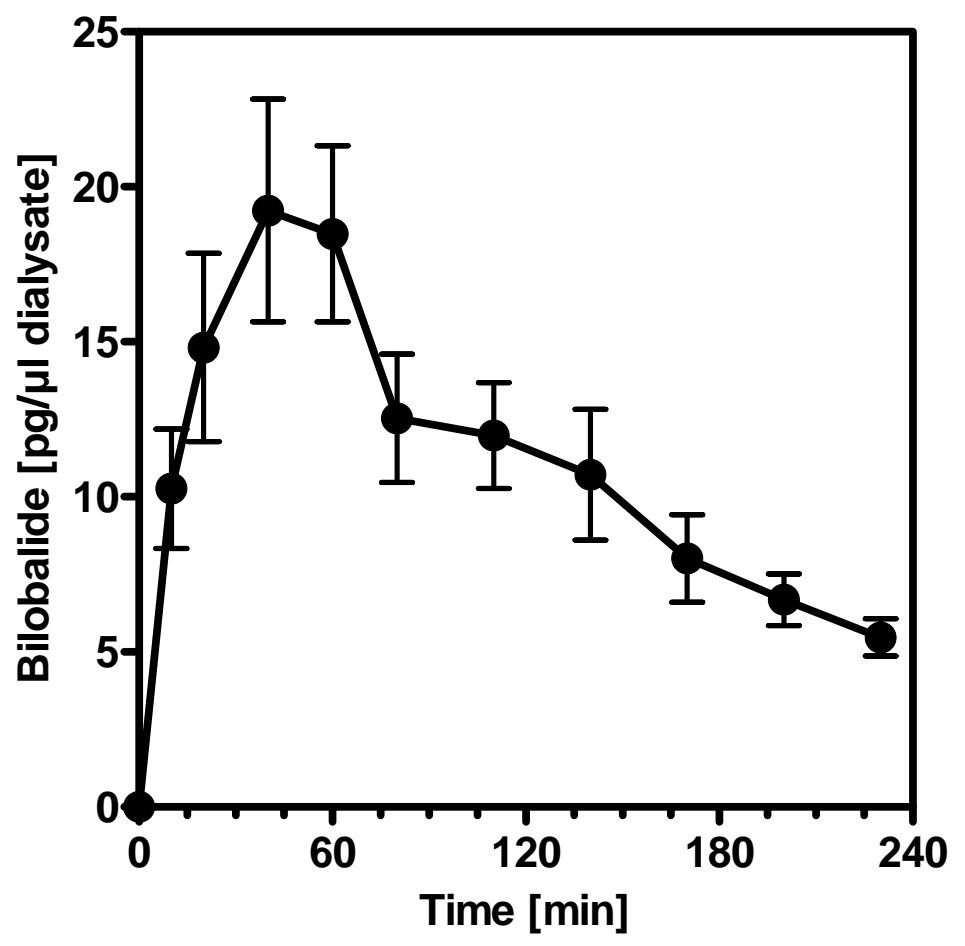

Figure 2. Extracellular concentrations of bilobalide in mouse striatum as measured by microdialysis. Time point zero represents the injection of bilobalide (10 mg/kg i.p.). Data are expressed as means $\pm \operatorname{SEM}(\mathrm{n}=6)$.

A

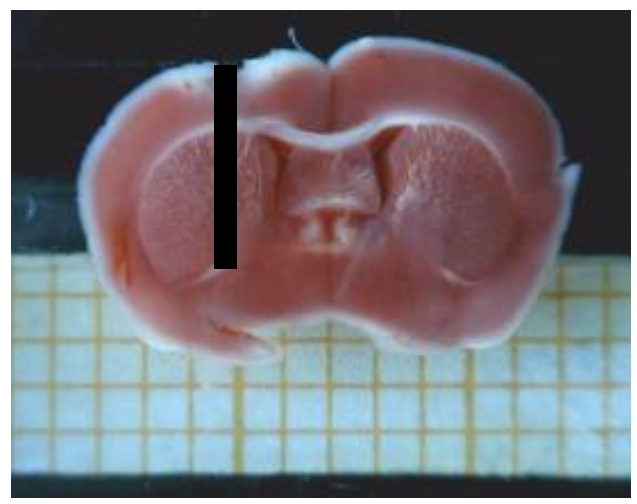

B

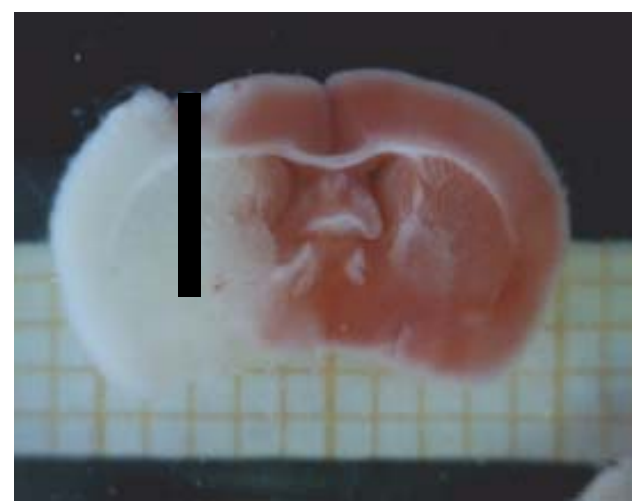

Figure 3. Brain slices stained with TTC. A represents a slice stained 24 hours after the microdialysis experiment in a control mouse to inspect the correct location of the probe in the striatum (see black bars) and $\mathbf{B}$ illustrates a slice stained $24 \mathrm{~h}$ after the ischemic insult.

\section{Brain levels of bilobalide under ischemic conditions}

In the first experiment with middle cerebral artery occlusion, $10 \mathrm{mg} / \mathrm{kg}$ bilobalide was given one hour before MCAO was induced. The early phase of the curve in Fig. 4 was similar to that obtained in healthy mice (Fig. 2); maximum brain levels were $14.0 \pm 7.9 \mathrm{pg} / \mu \mathrm{L}$ after 60 minutes (Fig. 4). After MCAO, bilobalide continued to be dialyzed out of the striatum at levels that were slightly lower than in the control experiment (Fig. 2). While the brain concentration of bilobalide was $0.67 \mu \mathrm{M}$ (Fig. 4; corrected for recovery) at the time of stroke induction, it was still $0.19 \mu \mathrm{M} 3$ hours later. Statistical analysis indicated that the difference between the curves of Fig. 2 and 4 was not significant ( $\mathrm{p}>0.5$, two-way ANOVA). 


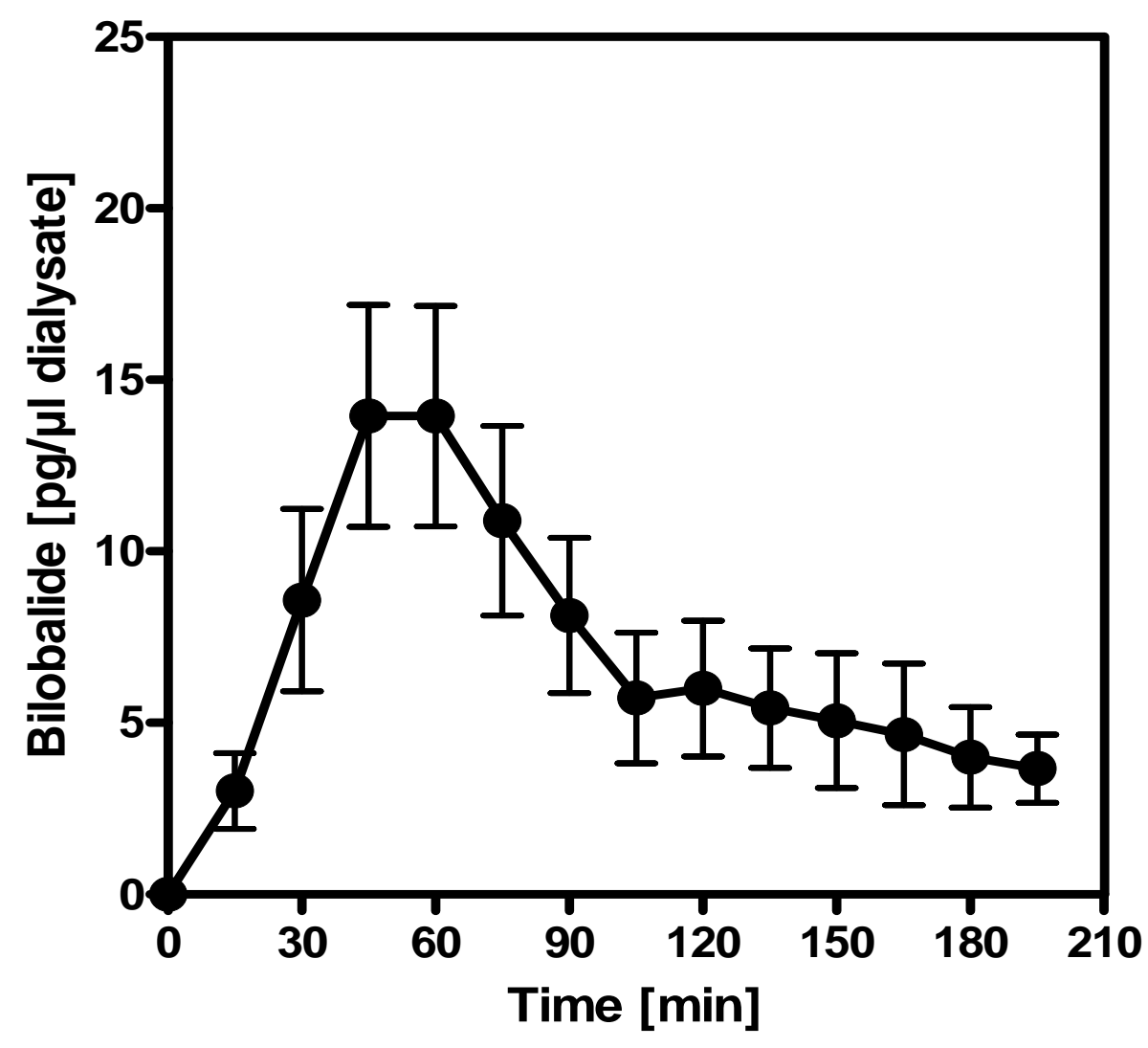

Figure 4. Influx and efflux of bilobalide in the striatum during the stroke experiment. Bilobalide (10 mg/kg) was given i.p. at time zero. $60 \mathrm{~min}$ after the drug application, the middle cerebral artery was occluded but dialysis continued. Data are expressed as means $\pm \operatorname{SEM}(n=6)$.

Finally, in the second experiment with MCAO, 10 $\mathrm{mg} / \mathrm{kg}$ bilobalide was given i.p. one hour after MCAO was induced. The goal of this experiment was to analyze the influx of bilobalide into the ischemic area after stroke. When given one hour after MCAO, bilobalide displayed a low but measurable influx into the striatal area which is in the core of the infarct. $15 \mathrm{~min}$ after application, the brain level of bilobalide was only $0.01 \mu \mathrm{M}$ (Fig. 5; corrected for recovery) but in spite of the occlusion of the MCA, the concentration of the drug increased within 120 minutes to a maximum of $1.8 \pm 0.9 \mathrm{pg} / \mu \mathrm{L}(0.08 \mu \mathrm{M})$ and remained at a plateau until the end of measurement $(180 \mathrm{~min}$; Fig. 5). At $60 \mathrm{~min}$ after bilobalide application, the plasma:brain ECF ratio was as low as 160:1 in this experiment, compared with a ratio of almost 6:1 when the drug was given before MCAO (see above).

\section{DISCUSSION}

Bilobalide, a constituent of Ginkgo biloba, has recently attracted considerable interest due to its potent neuroprotective properties $[8,11,22]$, and its pharmacokinetic properties are slowly unveiled. While several studies have reported plasma levels of bilobalide in humans and animals (see Introduction), little information was available for bilobalide levels in its target region, the brain. Very recently, we reported bilobalide concentrations in brain homogenates from animals that were dosed orally with Ginkgo extract [18]. In the present study, we extended this study by monitoring bilobalide in the extracellular space of the brain, using a microdialysis procedure. Extracellular levels are of major importance because bilobalide was reported to interact with GABAergic $[9,23]$ and glycinergic $[10,24]$ receptors that are exposed to the extracellular fluid. 


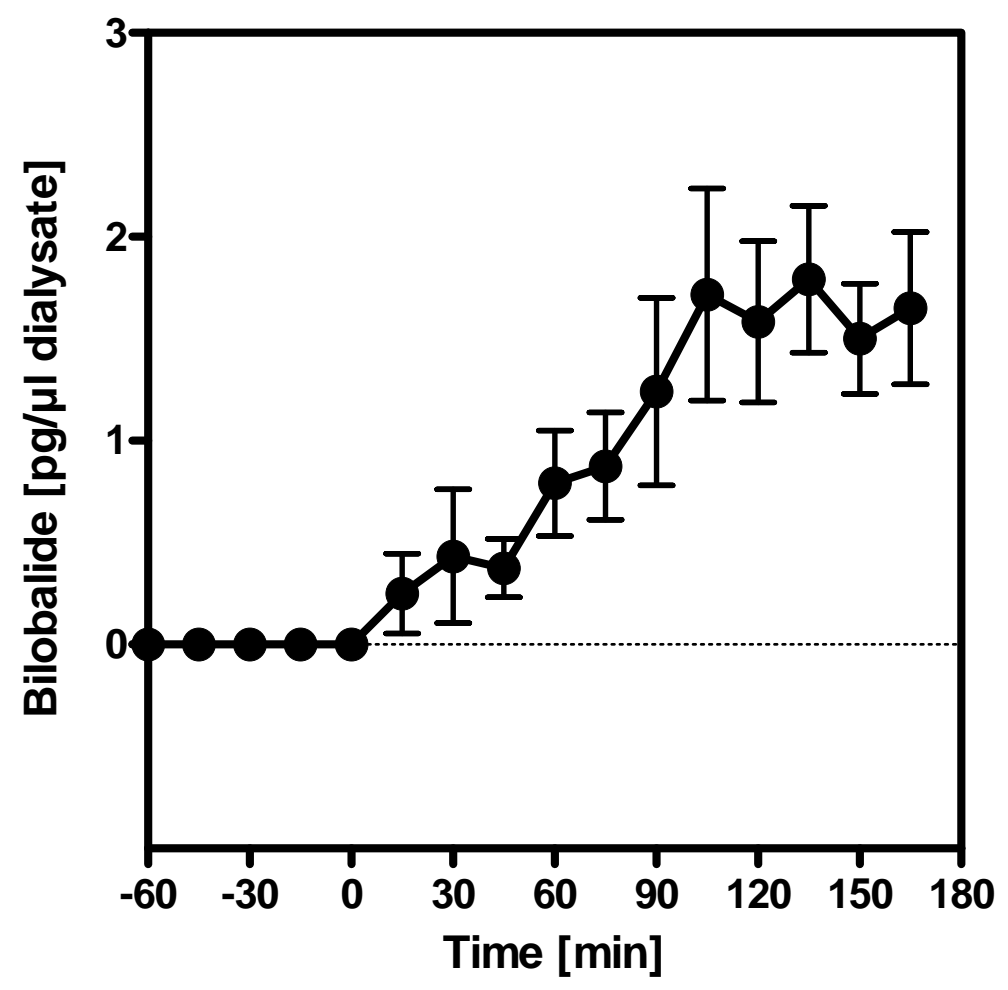

Figure 5. Influx of bilobalide into the ischemic striatum after MCAO. The MCA was occluded at time point -60 min and bilobalide $(10 \mathrm{mg} / \mathrm{kg})$ was given i.p. $60 \mathrm{~min}$ after stroke, at time point zero. Data are expressed as means $\pm \mathrm{SEM}$ $(n=6)$.

After parenteral administration of pure bilobalide, the drug was rapidly measurable in striatal microdialysates reaching levels of close to $1 \mu \mathrm{M}$ within 30-40 minutes (as estimated from in vitro-recovery).The bilobalide plasma level was $5.9 \mu \mathrm{M}$ after 60 minutes, a value that was close to our previous study [18] but somewhat higher than the plasma level measured in rats after oral dosing of pure bilobalide (1.6 $\mu \mathrm{M}$ after $20 \mathrm{mg} / \mathrm{kg}$ [17]). Thus, in our hands, bilobalide, which is poorly bound by albumin (Fig. 1), reaches $1 / 6$ of its plasma level in brain extracellular space within 40-60 minutes. These data clearly demonstrate that bilobalide crosses the blood-brain barrier easily and rapidly. The mechanism of brain entry is not known, but we speculate that bilobalide crosses the blood-brain barrier by passive diffusion. This assumption is supported by bilobalide's polarity and solubility, and by its behavior in in vitro-models such as Caco-2 cells $[25,26]$.

We determined a half-life of bilobalide in the brain close to 1.5 hours which is comparable to the plasma half-life in rats [18] and only slightly shorter than the plasma half-lives of 2-3 hours which were found in human studies [13-16]. This illustrates that efflux of bilobalide from the brain is equally rapid as influx into the brain resulting in brain concentration curves (Fig. 2) that resemble plasma concentration curves [18]. There is no evidence for accumulation of the drug in the brain.

A brain concentration of $1 \mu \mathrm{M}$, as measured in this study, is evidently sufficient to explain neuroprotective effects of bilobalide that were observed in vivo when similar doses of the drug were applied as in our study [4,8,27]. In in vitroexperiments in brain slices, we previously obtained $\mathrm{IC}_{50}$ values for bilobalide of $0.38 \mu \mathrm{M}$ (against hypoxia) and $2.3 \mu \mathrm{M}$ (against NMDA). Several other studies reported $\mathrm{IC}_{50}$ values for bilobalide of 1-5 $\mu \mathrm{M}$ for interactions with amino acid receptors and/or release $[9,23,28]$. The high potency of bilobalide in these in vitro-studies agrees with our present and earlier [18] findings of extra- and intracellular brain levels.

Our previous study on neuroprotection by bilobalide focused on its beneficial effects in acute neurodegeneration induced by stroke [8], and therefore, we presently investigated 
bilobalide levels in ischemic brain. Our data show that bilobalide, when given before MCAO, remains in the brain tissue for extended periods of time even after disruption of blood flow. This behavior is favorable for local neuroprotective effects in ischemic tissue. In contrast, after MCAO, bilobalide reaches ischemic tissue in a very low concentration, obviously because lack of blood flow in this area restricts transport of plasma bilobalide into the brain. While it is notable that small levels of bilobalide are measurable even after MCAO (likely due to collateral blood flow), it is clear from the present data that bilobalide is unlikely to reach effective levels in ischemic brain tissue when given post stroke. The obvious consequence for a potential therapy with bilobalide or Ginkgo extracts in stroke-prone patients is that the drug must be given before stroke occurs, i.e. in a preventive fashion.

Summarizing, our study defines the concentrations of bilobalide which can be obtained in brain extracellular fluid in healthy tissue and before and after stroke. Based on these data, beneficial neuroprotective effects of bilobalide in vivo are plausible, but for effectiveness in stroke, early (preventive) administration of the drug, possibly in a chronic fashion, is preferable.

\section{ACKNOWLEDGEMENTS}

We thank Dr. Willmar Schwabe GmbH for generously providing pure bilobalide. This study was financed by internal funds of Goethe University.

\section{REFERENCES}

[1] Oken BS, Storzbach DM, Kaye JA. The efficacy of Ginkgo biloba on cognitive function in Alzheimer disease. Arch. Neurol. 1998; 55: 1409-1415.

[2] Ramassamy C, Longpre F, Chrsiten Y. Ginkgo biloba extract (EGb 761) in Alzheimer's disease: is there any evidence ? Curr. Azheimer Res. 2007; 4: 253-262.

[3] Pierre S, Jamme I, Droy-Lefaix MT, Nouvelot A, Maixent JM. Ginkgo biloba extract (EGb 761) protects $\mathrm{Na}, \mathrm{K}-\mathrm{ATPase}$ activity during cerebral ischemia in mice. Neuroreport 1999; 10: 47-51.

[4] Chandrasekaran K, Mehrabian Z, Spinnewyn B, Drieu K, Fiskum G. Neuroprotective effects of bilobalide, a component of the Ginkgo biloba extract (EGb 761), in gerbil global brain ischemia. Brain Res. 2001; 922: 282-292.
[5] Paganelli RA, Benetoli A, Milani H. Sustained neuroprotection and facilitation of behavioral recovery by the Ginkgo biloba extract, EGb 761, after transient forebrain ischemia in rats. Behav. Brain Res. 2006; 174: 70-77.

[6] Klein J, Chatterjee SS, Loffelholz K. Phospholipid breakdown and choline release under hypoxic conditions: inhibition by bilobalide, a constituent of Ginkgo biloba. Brain Res. 1997; 755: 347-350.

[7] Weichel O, Hilgert M, Chatterjee SS, Lehr M, Klein J. Bilobalide, a constituent of Ginkgo biloba, inhibits NMDA-induced phospholipase $\mathrm{A}_{2}$ activation and phospholipid breakdown in rat hippocampus. Naunyn Schmiedebergs Arch. Pharmacol. 1999; 360: 609-615.

[8] Mdzinarishvili A, Kiewert C, Kumar V, Hillert M, Klein J. Bilobalide prevents ischemiainduced edema formation in vitro and in vivo. Neuroscience 2007; 144: 217-222.

[9] Kiewert C, Kumar V, Hildmann O, Rueda M, Hartmann J, Naik RS, Klein J. Role of GABAergic antagonism in the neuroprotective effects of bilobalide. Brain Res. 2007; 1128: 7078.

[10] Kiewert C, Kumar V, Hildmann O, Hartmann J, Hillert M, Klein J. Role of glycine receptors and glycine release for the neuroprotective activity of bilobalide. Brain Res. 2008; 1201: 143-150.

[11] Ahlemeyer B, Krieglstein J. Neuroprotective effects of Ginkgo biloba extract. Cell. Mol. Life Sci. 2003; 60: 1779-1792.

[12] Abdel-Kader R, Hauptmann S, Keil U, Scherping I, Leuner K, Eckert A, Müller WE. Stabilization of mitochondrial function by Ginkgo biloba extract (EGb 761). Pharmacol. Res. 2007; 56: 493-502.

[13] Biber A. Pharmacokinetics of Ginkgo biloba extracts. Pharmacopsychiatry 2003; 36 Suppl 1: S32-S37.

[14] Mauri P, Simonetti P, Gardana C, Minoggio M, Morazzoni P, Bombardelli E, Pietta P. Liquid chromatography/atmospheric pressure chemical ionization mass spectrometry of terpene lactones in plasma of volunteers dosed with Ginkgo biloba L. extracts. Rapid Commun. Mass Spectrom. 2001; 15: 929-934.

[15] Kressmann S, Müller WE, Blume HH. Pharmaceutical quality of different Ginkgo biloba brands. J. Pharm. Pharmacol. 2002; 54: 661-669.

[16] Woelkart K, Feizlmayr E, Dittrich P, Beubler E, Pinl F, Suter A, Bauer R. Pharmacokinetics of bilobalide, ginkgolide $\mathrm{A}$ and $\mathrm{B}$ after administration of three different Ginkgo biloba L. preparations in humans. Phytother. Res. 2010; 24: 445-450.

[17] Mauri P, Minoggio M, Iemoli L, Rossoni G, Morazzoni P, Bombardelli E, Pietta P. Liquid chromatography/atmospheric pressure chemical ionization ion trap mass spectrometry of terpene 
lactones in plasma of animals. J. Pharm. Biomed. Anal. 2003; 32: 633-639.

[18] Ude C, Paulke A, Noldner M, SchubertZsilavecz M, Wurglics M. Plasma and Brain Levels of Terpene Trilactones in Rats after an Oral Single Dose of Standardized Ginkgo biloba Extract EGb 761(R). Planta Med. 2010; epub DOI: $10.1055 / \mathrm{s}-0030-1250286$.

[19] Rangel-Ordonez L, Noldner M, SchubertZsilavecz M, Wurglics M. Plasma Levels and Distribution of Flavonoids in Rat Brain after Single and Repeated Doses of Standardized Ginkgo biloba Extract EGb 761(R). Planta Med. 2010; 76: 1683-1690.

[20] Kiewert C, Mdzinarishvili A, Hartmann J, Bickel U, Klein J. Metabolic and transmitter changes in core and penumbra after middle cerebral artery occlusion in mice. Brain Res. 2010; 1312: 101-107.

[21] Mdzinarishvili A, Geldenhuys WJ, Abbruscato TJ, Bickel U, Klein J, Van der Schyf CJ. NGP101 , a lipophilic polycyclic cage amine, is neuroprotective in focal ischemia. Neurosci. Lett. 2005; 383: 49-53.

[22] DeFeudis FV. Bilobalide and neuroprotection. Pharmacol. Res. 2002; 46: 565-568.
[23] Huang SH, Duke RK, Chebib M, Sasaki K, Wada K, Johnstob GA. Bilobalide, a sesquiterpene trilactone from Ginkgo biloba, is an antagonist at recombinant $\alpha_{1} \beta_{2} \gamma_{2 \mathrm{~L}} \mathrm{GABA}_{\mathrm{A}}$ receptors. Eur. J. Pharmacol. 2003; 464: 1-8.

[24] Ivic L, Sands TT, Fishkin N, Nakanishi K, Kriegstein AR, Stromgaard K. Terpene trilactones from Ginkgo biloba are antagonists of cortical glycine and $\mathrm{GABA}_{\mathrm{A}}$ receptors. J. Biol. Chem. 2003; 278: 49279-49285.

[25] Van Beek TA. Ginkgolides and bilobalide: their physical, chromatographic and spectroscopic properties. Bioorg. Med. Chem. 2005; 13: 50015012.

[26] Madgula VL, Avula B, Yu YB, Wang YH, Tchantchou F, Fisher S, Luo Y, Khan IA, Khan SI. Intestinal and blood-brain barrier permeability of ginkgolides and bilobalide: in vitro and in vivo-approaches. Planta Med. 2010; 76: 599-606.

[27] Krieglstein J, Ausmeier F, Elabhar H, Lippert K, Welsch M, Rupalla K, Henrich-Noack P. Neuroprotective effects of Ginkgo biloba constituents. Eur. J. Pharm. Sci. 1995; 3: 39-48.

[28] Davies JA, Johns L, Jones FA. Effects of bilobalide on cerebral amino acid neurotransmission. Pharmacopsychiatry 2003; 36 Suppl 1: S84-S88. 